\title{
4. Theorising about the Life Cycle of IT Use: An appropriation perspective
}

\author{
Justin Fidock \\ RMIT University \\ Jennie Carroll \\ RMIT University
}

\begin{abstract}
This chapter argues that theorising about the whole life cycle of information technology (IT) use is underdeveloped. Theories that explain one or more phases of the life cycle of IT use are discussed and critiqued and a candidate theory for understanding the whole life cycle identified: the model of technology appropriation (MTA). The MTA incorporates many of the strengths of other models but has a shortcoming with respect to explaining how and why changes in patterns of use occur over the life cycle. To address this weakness, theories of change are examined and incorporated with the MTA. It is argued that the resulting model provides a more complete description and explanation of the IT use life cycle.
\end{abstract}

\section{Introduction}

Understanding and predicting the use of information systems (IS) are two of the central concerns for IS researchers and practitioners (Benbasat and Zmud, 2003; DeLone and McLean, 1992; Karahanna et al., 1999; McLean et al., 2002; Trice and Treacy, 1988). A system that is under-utilised, misused or avoided altogether will not achieve the intentions of its designers or those who have procured the system. Given its centrality for both researchers and practitioners, it is important to identify the ways in which researchers choose to theorise about use. This is because the choice of theory influences what is included or excluded from consideration. If a theory were not developed in the context of examining the whole use life cycle then its ability to explain the whole would likely be constrained. The central premise examined in this chapter is that theorising about the whole life cycle of IT use is underdeveloped. An important corollary of this premise is that understanding the life cycle as a whole will make 
additional contributions to IS research and practice beyond those provided by theory focused on only a portion of the life cycle. Furthermore, an enhanced understanding of the life cycle will assist in identifying the limits of applicability of partial views of the life cycle.

In this chapter the life cycle of IT use is briefly described. Theories used to explain use, and the life cycle of use more broadly, are then discussed and critiqued and a candidate theory for understanding the whole life cycle identified: the model of technology appropriation (MTA). The MTA is seen to incorporate many of the strengths of the other models but is somewhat lacking with respect to explaining the how and why of changes in patterns of use over the life cycle. Additional theories or motors of change are therefore introduced-teleology, dialectic and evolution - which are incorporated along with the MTA as a way of addressing this weakness. The chapter concludes by arguing that the revised MTA offers a richer and more complete description and explanation of the use life cycle than has been available hitherto.

\section{The Life Cycle of IT Use}

The life cycle of IT use describes the phases through which use of an IT artefact transitions - from the period prior to use through to continued or discontinued use. How the life cycle is represented is influenced by the ways in which use is conceptualised and examined. When use is conceptualised as the extent of use, the life cycle entails pre-use, initial use and continued use (see Figure 4.1). The extent of use is commonly assessed via self-reporting measures of the frequency or amount of use. Use is framed as a thing that changes in value but not in identity or character. Alternatively, the life cycle can be understood in terms of the nature of use and includes adaptive use and stabilised use (see Figure 4.2). The nature of use is viewed as potentially taking qualitatively different forms such as adaptation, stabilisation and appropriation and is often identified using qualitative methods (Carroll, 2004). The diagram in Figure 4.3 captures how use is represented and explored from the two perspectives combined. 


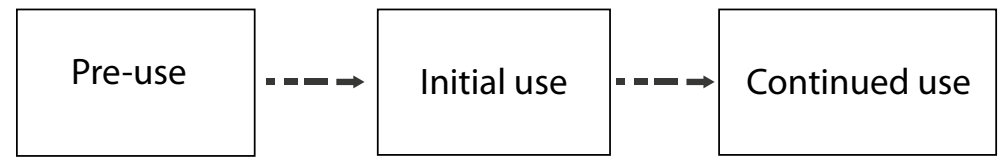

Figure 4.1 The Extent of Use Life Cycle

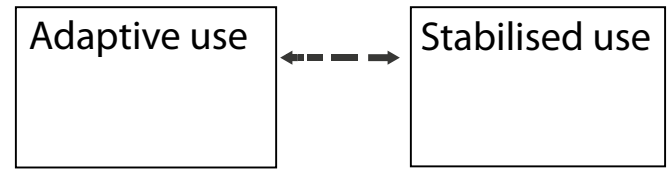

Figure 4.2 The Nature of Use Life Cycle

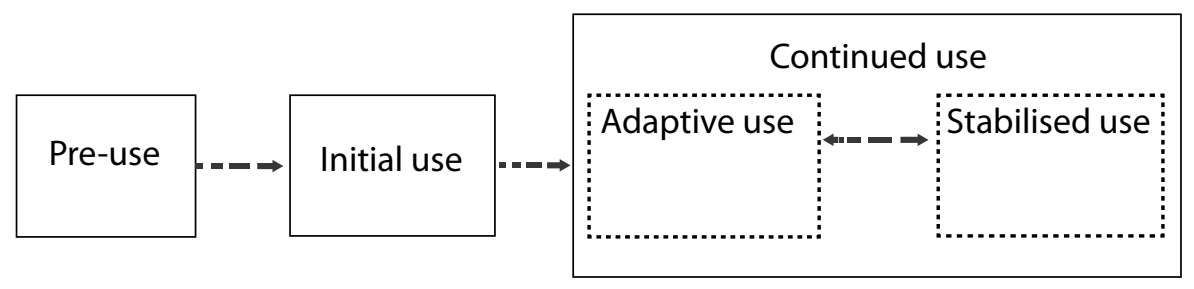

Figure 4.3 The Life Cycle of IT Use

Pre-use captures the period prior to a potential user starting to use a technology to support particular activities and practices (Bhattacherjee and Premkumar, 2004). This phase involves a user becoming acquainted with some of the features offered by the technology when first exposed to it, or following information about a proposed technology, as might occur via word of mouth. Attention is given to pre-use in situations where use is not well established, such as for new or prototype systems. In particular, researchers have attempted to predict future use by assessing users' intentions to engage in system use (behavioural intention) (Agarwal and Prasad, 1998; Davis et al., 1989; Karahanna et al., 1999; Mathieson, 1991; Taylor and Todd, 1995a, 1995b).

Pre-use is followed by initial use (Jasperson et al., 2005), during which time the user starts to employ features of the technology to support the conduct of tasks, such as might occur during a training course (Burton-Jones and Straub, 2006). In assessing initial use, researchers have used a variety of lean surveybased measures including frequency of use and time spent using the system (Adams et al., 1992; Al-Gahtani and King, 1999; Davis, 1989; Davis et al., 1989; Hubona and Geitz, 1997; Igbaria, 1990; Igbaria et al., 1989, 1997; Raymond, 1985; Roberts and Henderson, 2000). To a lesser extent, researchers have used hardware (DeLone and McLean, 1992) and software (Venkatesh et al., 2003) monitors to record actual system use. 
Adaptive use occurs as a user engages in a more detailed exploration of the technology through applying the technology to support work practices within particular use contexts (Constantinides and Barrett, 2006; Desouza et al., 2007; Trigg and Bødker, 1994). Adaptations are made to the technology by a particular user to support their specific practices and use context, and adaptations are also made to user practices and the use context in response to the technology (Trigg and Bødker, 1994; Tyre and Orlikowski, 1994). Adaptations to the technology itself have been described using such terms as personalisation (Desouza et al., 2007), customisation (Desouza et al., 2007; Mackay, 1990a, 1990b; Trigg and Bødker, 1994), inventions (Desouza et al., 2007), reinvention (Johnson and Rice, 1984; Rice and Rogers, 1980; Rogers, 1995) and tailoring (Trigg and Bødker, 1994). Adaptations to work practices include work-arounds and improvisation (Hayes, 1999). Researchers also describe mutual changes in the technology and associated practices through such concepts as mutual adaptation (Boersma and Kingma, 2005; Carroll, 2004; Leonard-Barton, 1988; Majchrzak, et al. 2000), mutual adjustment (Rose and Jones, 2005), co-adaptation (Mackay, 1990a, 1990b), coevolution (Kim and Kaplan, 2006), structuring (Barley, 1986; DeSanctis and Poole, 1994) and the process of appropriation (Carroll 2004; Mendoza et al., 2008).

Stabilised use entails the routinisation of patterns of use (Rogers, 1995; Trigg and Bødker, 1994; Tyre and Orlikowski, 1994). Routines that develop might change in response to discrepant events or new discoveries by users (represented by the two-way arrow between adaptation and stabilisation) (Mendoza et al., 2005; Tyre and Orlikowski, 1994). Such stabilised use is also referred to as structured (Trigg and Bødker, 1994), integrated, appropriated (Carroll, 2004), infused (Sundaram et al., 2007) or institutionalised use (Orlikowski, 1992).

Continued use is an alternative to adaptive and stabilised use when the nature of use is not explored. It is the period of use that follows initial or first use (Hsieh et al., 2008; Karahanna et al., 1999; Pollard, 2003; Rogers, 1995; Shih, 2008; Venkatesh et al., 2003). Like the initial use phase, frequency of use and time spent using the system are often assessed.

\section{Theories to Explain the Life Cycle}

There are a large number of candidate theories that could be drawn on to assist in describing, explaining or predicting one or more aspects of the IT use life cycle. The theories discussed below have been selected based on their alignment with one or more of the key phases associated with the life cycle, but also based on their prominence within the IS research community. The key theories considered in this chapter are technology acceptance, innovation diffusion, 
structuration and the model of technology appropriation. A selection of studies drawing on each of these theories is summarised in Table 4.1, along with the phases of the use life cycle considered.

Table 4.1 Categorisation of Some Theories and Studies of Technology Use by Life-Cycle Phase

\begin{tabular}{|c|c|c|c|c|c|}
\hline & \multicolumn{5}{|c|}{ Phase of IT use life cycle } \\
\hline & Pre-use & $\begin{array}{c}\text { Initial } \\
\text { use }\end{array}$ & $\begin{array}{c}\text { Adaptive } \\
\text { use }\end{array}$ & $\begin{array}{c}\text { Stabilised } \\
\text { use }\end{array}$ & $\begin{array}{c}\text { Continued } \\
\text { use }\end{array}$ \\
\hline $\begin{array}{l}\text { Technology } \\
\text { acceptance }\end{array}$ & $\checkmark$ & $\checkmark$ & & & 12 \\
\hline Davis (1989) & & $\checkmark$ & & & 15 \\
\hline Davis et al. (1989) & & $\checkmark$ & & & 16 \\
\hline Venkatesh et al. (2003) & & $\checkmark$ & & & is \\
\hline $\begin{array}{l}\text { Taylor \& Todd (1995a, } \\
\text { 1995b) }\end{array}$ & $\checkmark$ & & & & 12 \\
\hline Innovation diffusion & $\checkmark$ & & & & 14 \\
\hline Agarwal \& Prasad (1998) & $\checkmark$ & & & & i \\
\hline Karahanna et al. (1999) & $\checkmark$ & & & & $1 \checkmark$ \\
\hline Moore \& Benbasat (1991) & & & & & 15 \\
\hline Structuration & & & $\checkmark$ & $\checkmark$ & i \\
\hline DeSanctis et al. (2000) & & & $\checkmark$ & 2 & 1 \\
\hline $\begin{array}{l}\text { Model of } \\
\text { technology } \\
\text { appropriation }\end{array}$ & $\checkmark$ & $\checkmark$ & $\checkmark$ & $\checkmark$ & i \\
\hline Carroll et al. (2003) & $\checkmark$ & $\checkmark$ & $\checkmark$ & & 1 \\
\hline Mendoza et al. (2005) & $\checkmark$ & $\checkmark$ & $\checkmark$ & $\checkmark$ & 1 \\
\hline Mendoza et al. (2008) & $\checkmark$ & $\checkmark$ & $\checkmark$ & $\checkmark$ & i \\
\hline
\end{tabular}

Table 4.1 suggests that very few researchers have considered use over the whole life cycle (four phases), or even over three phases. The majority of research on the use of IT artefacts only provides a partial view of use across the life cycle. Technology acceptance and innovation diffusion perspectives attend to the extent of the use life cycle (see Figure 4.1). Structuration focuses on the nature of the use life cycle (see Figure 4.2). Only studies drawing on the MTA cover the whole life cycle, from pre-use through to stabilised use. Our attention now turns to the descriptive and explanatory potential offered by each of these theoretical perspectives. 


\section{Technology Acceptance}

The theoretical grounding for much of the research into user acceptance comes from the technology acceptance model (TAM) developed by Davis et al. (1989), Venkatesh et al. (2003) and Venkatesh and Bala (2008). This model is an adaptation of the theory of reasoned action (TRA), which sees beliefs and attitudes as antecedents of future behavioural responses, such as actual system use (Ajzen, 1985; Davis, 1993). TAM differs from the TRA by identifying the role of external variables more explicitly and by identifying two particular belief constructs as particularly relevant in the IS domain-namely, perceived usefulness and perceived ease of use. These beliefs are seen-either directly or indirectly and via attitudes towards using the technology - to shape users' intentions to employ a system, which in turn determines system use, which is usually conceptualised as the extent of use (Davis, 1989; Davis et al., 1989). Figure 4.4 presents TAM as represented by Davis et al. (1989). An important feature of the model is its focus on prospective users, as evidenced by the definition of perceived usefulness as 'a prospective user's subjective probability that using a specific application system will increase his or her job performance within an organisational context'. In subsequent studies the model and associated variables have been applied to both prospective and current users of systems, through changing the tense of scale items (for example, Venkatesh et al., 2003).

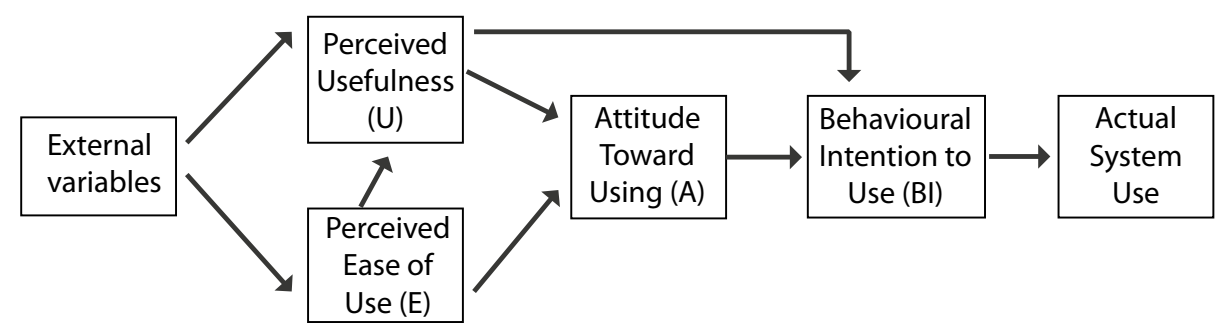

Figure 4.4 The Technology Acceptance Model

Source: Davis et al. (1989, p. 985).

The research by Davis (1989) and colleagues (Davis et al., 1989) on technology acceptance and its antecedents (perceived usefulness and ease of use) has had, and continues to have, an enormous influence on IS research. This is a positive in the sense that it has laid the foundation for a cumulative tradition whereby there has been widespread and persistent use of the two key variablesperceived ease of use and usefulness - in a diverse range of use contexts and technologies. In addition, statistical methods such as regression analysis and structural equation modelling that have been employed in these numerous studies to test hypothesised links between these variables and use afford researchers statistical control that can be construed as a form of experimentation 
(Lee, 1999). This can assist in cutting through the complexity of the phenomena of interest. Such statistical experimentation has assisted in confirming the central role of perceived usefulness, and to a lesser extent perceived ease of use, in predicting behavioural intention and use. The parsimony of TAM, however, and its apparent power in explaining a fair portion of the variance, appear to have led to an overemphasis on the extent of variance explained rather than the untidy and messy unexplained variance. A focus on pre-specified variables and the explained variance in models such as TAM leads to a neglect of context, which removes the capacity to understand the 'subtle nuances of interaction that are critical in apprehending what is really occurring' (Pfeffer, 1982, p. 75). As a result, whilst levels of perceived usefulness and ease of use would assist managers with understanding influences on intentions and use in a general sense, the information provided would say little about the specific contextual factors operating on users of the particular technology. Even when attention is constrained to explained variance there are methodological issues associated with questionnaires (Sharma and Yetton, 2001; Straub and Burton-Jones, 2007). A meta-analysis by Sharma and Yetton (2001, p. 1170) found that 'the average correlation between "perceived usefulness" and "use" is 0.26 in studies employing behavioral measures of use and 0.56 in studies employing perceptual measures of use'. This effect, whereby perceptual or self-reporting measures of use lead to higher correlations, is referred to as self-generated validity (Taylor and Todd, 1995b). It is proposed that 'when survey respondents are asked about issues to which they have given very little prior thought, they...are apt to use answers to earlier survey questions as the bases for responses to later questions, resulting in inflated causal linkages' (Taylor and Todd, 1995b, p. 171). So, rather than describing cognitions and behaviours, researchers run the risk of creating and even changing them (Ogden, 2003; Pfeffer, 1982; Taylor and Todd, 1995b).

The development of TAM was driven by a desire to predict and explain human behaviour (Davis et al., 1989). TAM and associated acceptance models such as UTAUT are cognitive-rational theories that assume system use is driven by the intentionality of users, with users' intentions being informed by their beliefs and attitudes towards the technology of interest (Pfeffer, 1982). To the extent that behaviour is driven by intention then such models have some utility; however, this class of theories has been widely criticised in the social and management sciences more broadly (Abraham and Sheeran, 2004; Ogden, 2003; Pfeffer, 1982). Such theories have been criticised for

- not helping to explain the variety of things people use, such as the range of features employed on a system, versus just explaining a particular behaviour of interest, such as extent of system use (Abraham and Sheeran, 2004)

- creating and shaping rather than describing users' cognitions and behaviours (Ogden, 2003; Pfeffer, 1982; Taylor and Todd, 1995) 
- often assuming unidirectional causality and the associated implication that beliefs and attitudes come before behaviour, despite evidence that behaviour also shapes attitudes and beliefs (Mintzberg and Westley, 2001; Pfeffer, 1982); people do not always think or choose before taking action, such as when engaged in habitual behaviours; when asked about the reasons for their behaviours this could reflect retrospective rationality, not prospective rationality as is assumed in such models (Pfeffer, 1982)

- providing a weak source of explanation as to why the relationships identified are significant (Hovorka et al., 2008; Pfeffer, 1982). As Hovorka argues, 'a falling barometer allows inference that there has been a drop in air pressure, but the drop cannot be explained by referring to the barometer' (p. 32). In the context of TAM, the source of explanation is the set of variables statistically identified as linked to intentions and behaviours. Such statistical inferences only afford partial understanding of the phenomena of interest. Whilst the variables might predict use, their ability to explain use is limited.

Another limitation of user acceptance models like TAM and UTAUT is that time is viewed as part of the background (Van de Ven and Poole, 2005). The amount of time is uncritically applied as an indicator of experience, familiarity and routinisation (Venkatesh et al., 2003), or the interest in time is limited to providing distance between two measurements so as to determine the strength of the causal relationship between behavioural intention and system use (for example, Davis, 1989; Taylor and Todd, 1995b). These limitations raise serious questions about the utility of TAM and related models for understanding the life cycle of use, and it is for these reasons, and others, that there have been widespread calls to go beyond TAM (Bagozzi, 2007; Baron et al., 2006; Benbasat and Barki, 2007; Carayannis and Turner, 2006; Dishaw and Strong, 1999; Goodhue, 2007; Hirschheim, 2007; Lucas et al., 2007; Mendoza et al., 2005; Schwarz and Chin, 2007; Silva, 2007; Straub and Burton-Jones, 2007). Nevertheless, such models can assist in drawing inferences about the salience and strength of particular influences on intentions and use, which might be particularly relevant at the pre-use and initial use phases when users might be expected to be more driven by intentions (Venkatesh et al., 2003).

\section{Diffusion of Innovation}

The literature on the diffusion of innovations is diverse and populated by a variety of different models that address individual and organisational decision points and activities (Cooper and Zmud, 1990; Hage and Aiken, 1970; Johnson and Rice, 1984; King, 1990; Kwon and Zmud, 1987; Rice and Rogers, 1980; Rogers, 1995; Wolfe, 1994). One researcher in particular has, however, dominated research into the diffusion of innovations for decades: Everett Rogers. In his book Diffusion of Innovations (1995), Rogers presents models of the innovation 
diffusion process that emphasise either the individual or the organisational processes, as well as models of adoption and implementation. Of particular relevance here is his model that describes the innovation diffusion process for individuals (see Figure 4.5). The model has five stages

- knowledge: the stage where a potential adopter becomes aware of an innovation and develops some understanding of its capabilities

- persuasion: the stage where the formation of either positive or negative attitudes towards an innovation occurs

- decision: the stage where a person decides either to adopt or to reject an innovation

- implementation: the stage where a person puts an innovation to use

- confirmation: the stage where either the innovation decision is reinforced or an earlier decision to adopt or reject a system is reversed.

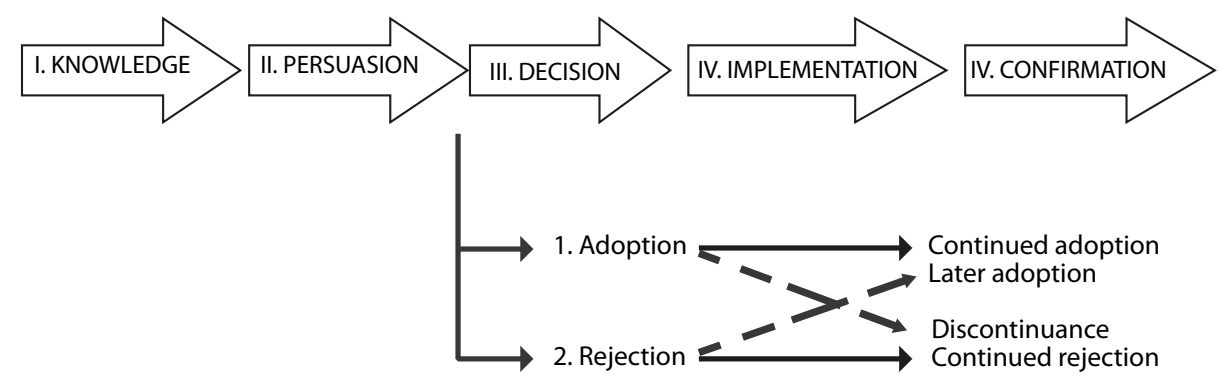

Figure 4.5 A Model of Stages in the Innovation Decision Process

Source: Rogers (1995, p. 163).

In addition to these stages, Rogers also identifies five key attributes of innovations that influence user adoption at the persuasion stage

- relative advantage: the extent to which an innovation is viewed as better than its predecessor

- compatibility: the extent to which an innovation is viewed as consistent with the extant needs, values, beliefs and experiences of potential adopters

- complexity: the extent to which an innovation is viewed as difficult to use

- observability: the extent to which the impacts of an innovation are visible to others

- trialability: the extent to which an innovation can be experimented with prior to the adoption decision.

The above model and associated five key attributes have been drawn on extensively in the IS literature (for example, Agarwal and Prasad, 1998; 
Karahanna et al., 1999; Kautz and Larsen, 2000; Kraut et al., 1998; Lin and Lee, 2006; Moore and Benbasat, 1991; Pollard, 2003; Prescott and Conger, 1995; Rice and Rogers, 1980; Shih, 2008). They support exploration of influences prior to, during and after the adoption decision. Furthermore, the model draws a distinction between initial use, during which time the innovation is put to use (implementation stage), and continued/discontinued use (confirmation stage) (Pollard, 2003).

Rogers' model and other models of the innovation adoption and diffusion process (Carayannis and Turner, 2006; Cooper and Zmud, 1990; Hage and Aiken, 1970; Johnson and Rice, 1984; Kwon and Zmud, 1987; Nord and Tucker, 1987; Saga and Zmud, 1994) are life-cycle models. As such, change is explained by reference to the sequence of phases through which the system of interest passes (Van de Ven and Poole, 1995). Such life-cycle models tell us little, however, about the underpinning mechanisms that generate the behaviour observed, and, with some exceptions (for example, Rogers), tend to be analytically or metaanalytically derived rather than emerging from first-hand longitudinal research on the adoption and diffusion of technologies.

A counter to this argument might be to say that explanation is provided by assessing users' perceptions of a system using the five key attributes. While studies investigating the influence of these attributes help to identify important influences on adoption and use, they often do so from the perspective of crosssectional or 'factor'-based research (for example, Agarwal and Prasad, 1998; Lin and Lee, 2006). As a consequence of this methodological constraint the clearly process-orientated nature of innovation diffusion theories can only be partially examined and explained (McMaster and Wastell, 2005). A further issue with these five key attributes is the assumption that they primarily operate at the persuasion stage, when there is clear evidence that such affective attributes operate after the adoption decision (Karahanna et al., 1999).

There are two additional criticisms that have been directed at the innovation diffusion literature. Historian David Edgerton argues that views of innovation tend to be centred on innovations as they are emerging, not after they have long been in use: 'Even as new technologies revolutionize everything from health care to media to warfare, it's important to remember that our world runs primarily on products and technologies long in use' (Baker, 2007). Rogers (1995, p. 172) also criticises innovation research for having a strong pro-innovation bias, going on to say that 'investigation of rejection behavior of all kinds has not received much scientific attention'.

Diffusion of innovation research provides a basis upon which to investigate the life cycle of use; however, it does so from a perspective that privileges the new over the taken for granted, adoption over rejection, and factor over process. 


\section{Structuration}

Information systems researchers have extensively drawn on structuration theory - in particular, Anthony Giddens' structuration theory (1986) - to assist in explaining the interactions between technology and people embedded in social contexts, such as organisations (Jones and Karsten, 2008). Giddens was concerned with transcending the dichotomous logic associated with dominant traditions within social theory that privileged either the agency of individuals or the structures that limit human choices and action, such as properties of society. Structurational theories seek to reconcile tensions between individual and societal-level explanations of social phenomena through seeing both as being mutually constituted (Jones and Karsten, 2008). Social phenomena, from a structurational perspective, are the product of both structure and agency: 'human agents draw on social structures in their actions, and at the same time these actions serve to produce and reproduce social structure' (Jones and Karsten, 2008, p. 129). These structures, or more particularly the structural properties of social systems, consist of rules and resources used by individuals in their interactions. 'These rules and resources mediate human action, while at the same time they are reaffirmed through being used by human actors' (Orlikowski, 1992, p. 404). Whilst this process of mutual constitution enables change in social systems, Giddens' argued that continual change is countered by a desire amongst social actors for ontological security, a belief that their personal or professional identities will be maintained and that actions and events in the surrounding social and material environment will not undermine their identity. Predictability and routinisation are therefore of central importance in maintaining the identities of social actors (Jones and Karsten, 2008).

Giddens' structuration theory has been translated into IS in a variety of ways. The appeal of this theory for IS researchers is that it provides a means of adopting a non-dichotomous logic (Pozzebon, 2004). For IS researchers adopting a structurational perspective, the structure/agency dichotomy is overcome by framing the relationship between technology and humans as the process through which humans shape and are shaped by IT artefacts (Orlikowski, 1992; Poole and DeSanctis, 1990). One particularly dominant translation of Giddens' theory within IS is Poole and DeSanctis's adaptive structuration theory (Poole and DeSanctis, 1990).

Adaptive structuration theory (AST) emerged out of research focused on social interactions and processes associated with the use of group decision support systems (DeSanctis and Poole, 1994; Poole and DeSanctis, 1990). DeSanctis and Poole (1994) present a number of different propositions associated with their modification of structuration theory for IS; however, two propositions are particularly salient as they bring to the surface three key concepts associated with AST (highlighted in italics). 
- Advanced information technologies (AITs) 'provide social structures that can be described in terms of their features and spirit. To the extent that AITs vary in their spirit and structural feature sets, different forms of social interaction are encouraged by the technology' (p. 128; italics added).

- 'New social structures emerge in group interaction as the rules and resources of an AIT are appropriated in a given context and then reproduced in group interaction over time' (p. 129; italics added).

Structural features represent particular capabilities, or rules and resources, provided by the system. Structural features 'govern exactly how information can be gathered, manipulated and otherwise managed by users' (p. 126). Underlying these structural features is the way in which users should act when employing the system, referred to as the spirit. The spirit of a technology reflects, amongst other things, the designers' intentions; however, the ways in which users appropriate or implement the technology are not necessarily determined by the technology design. The particular structural features selected by users represent only a subset of those embedded within a technology. Users therefore are able to appropriate the capabilities of a system in a wide variety of ways (DeSanctis and Poole, 1994). Appropriation is here understood to be the 'immediate, visible actions that evidence deeper structuration processes' (p. 128). Analysis of appropriation moves therefore provides a way of examining the underlying social processes.

One of the concerns about AST is its view of technology as encapsulating social structures in the form of structural features and spirit. This view runs counter to the position adopted by Giddens, who argued that social structures do not have an existence independent of the action of humans (Markus and Silver, 2008). A further concern is the apparent anthropomorphism of the spirit concept, which is described as somehow conveying or embodying the designers' intentions (Markus and Silver, 2008). Another issue with AST is that research that has operationalised one or more of its key constructs has failed to identify strong relationships with common influences such as ease of use and usefulness; instead the findings are inconsistent and only moderate in strength (Chin et al., 1997; DeSanctis and Poole, 1994; DeSanctis et al., 2000; Gopal et al., 1992; Salisbury et al., 2002). AST also appears to have been predominantly applied to group or collaborative information systems such as group decision support systems and computer-mediated communication (Jones and Karsten, 2008), rather than less socially mediated systems.

A more general criticism of structurational approaches is that readers experience difficulties in readily understanding the meaning of the text. Information systems is an applied discipline and it has been argued that the accessibility of theories is an important consideration in judging relevance (Rosemann and Vessey, 2008). Structuration theory and AST are frequently difficult to comprehend and employ concepts in ways that bear little relation to their more common forms of use. For example, Giddens' definition of structure, defined in terms of rules and resources, is particularly idiosyncratic (Jones and Karsten, 2008). 
Researches drawing on Giddens' theory, in particular his views on the importance of ontological security, follow him in privileging routinisation and the maintenance of individual identities over adaptation and transformation (Chu and Robey, 2008). While adaptation has its place, it is subordinate to stability. This position is consistent with empirical research suggesting that over time adaptations become structured (for example, Carroll, 2004; Trigg and Bødker, 1994; Tyre and Orlikowski, 1994). Research has, however, also found that adaptations can again occur (Mendoza et al., 2005, 2007; Tyre and Orlikowski, 1994).

\section{Model of Technology Appropriation (MTA)}

The model of technology appropriation (MTA) was developed by Carroll et al. (2002c) to assist with understanding the process of appropriation through which technology is evaluated by people over time and adopted, adapted and incorporated into their work practices, and through which the design of technology is completed through use (Figure 4.6).

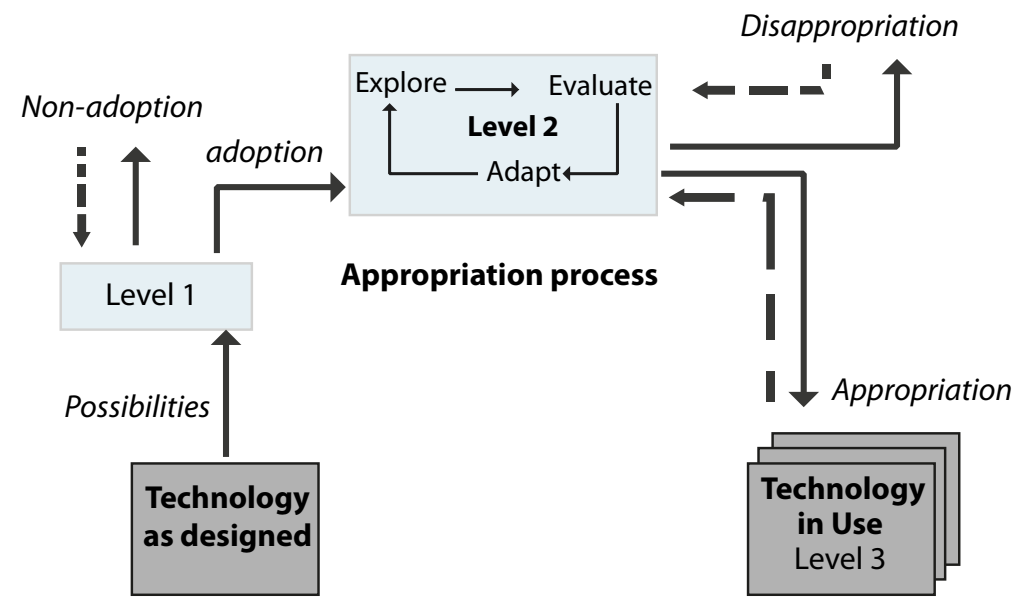

Figure 4.6 The Model of Technology Appropriation

Source: Carroll (2004, p. 5).

The MTA is intended to be a generic model of technology appropriation that can be tailored for particular technologies and user cohorts (Carroll, 2004). It has been employed to assist in describing the appropriation of mobile phones, bibliographic software, Short Messaging Service (SMS), email, customer relationship management software, open source software and a learning management system (Carroll et al., 2002a, 2003a, 2003b, 2005; Herszfeld et al., 
2003; Heung, 2002; Mendoza et al., 2007; Nor Zairah and Rose Alinda, 2007). Throughout the process of appropriation various influences shape the beliefs, attitudes and behaviours of users towards the technology.

In the model there are three levels of evaluation that correspond with different phases of the appropriation process (Carroll et al., 2002a). As can be seen in Figure 4.6, when first encountering a technology during the initial exposure phase, users are confronted with the technology as intended by its designer, or 'technology as designed', which 'has features, capabilities and an underlying theory or spirit' about how the technology should be employed (p. 3). From the users' perspective, the technology presents a variety of possibilities for addressing their particular concerns, which might or might not align with those identified by the designers. During users' initial exposure to the technology a series of influences shapes their evaluations and decisions whether or not to adopt the technology. In the case of an information system, influences on users might include the graphical user interface and system functionality. The outcome of this level-one evaluation is the establishment of certain expectations about what the technology can deliver, which leads to either non-adoption or the user choosing to persist with exploring the technology thereby continuing the appropriation process. In the case where the user chooses not to adopt the technology there might be circumstances that cause them to re-evaluate the technology at some later time (represented by the dashed arrow from nonadoption to level one in Figure 4.6).

At the next phase of the appropriation process users evaluate the technology more deeply through exploring and using the technology (level-two evaluation) (Carroll, 2004; Herszfeld et al., 2003). They come to learn how the technology can support their practices through the provision of particular functionality. As users explore and learn about the technology they also adapt their practices associated with the technology as well as adapting the technology itself. During this adaptation phase there is again a variety of influences that serves to encourage or discourage continued appropriation - for example, the extent to which the technology enhances the user's performance.

In the final phase a state of appropriation or stabilisation is reached, whereby the practices around the use of the technology become routine, and no further adaptations to the technology occur (Carroll, 2004). The technology becomes integrated with work practices, is part of users' taken-for-granted experience of work, and is just another part of the work landscape, referred to as 'technology in use'. It is during this phase that the design can be said to be fixed, although this might not be permanent (Mendoza et al., 2005) (see dotted arrow back to level two). The state of appropriation is maintained as long as users' ongoing evaluation of the 'technology in use' continues to reinforce persistent use. The particular patterns of use that users settle on are assumed to vary across 
individuals, conveyed by the tiled boxes associated with 'technology in use' in Figure 4.6. These level-three evaluations are shaped by various influencesfor example, the attitudes and behaviours of one's peer group towards the technology or the performance of the technology. Users' persistent use and ongoing incorporation of the technology with their work practices are, however, subject to modification if their evaluation of the technology changes. If this occurs then users might return to level two and the technology could be disappropriated or rejected.

The two primary strengths of the MTA are that it covers the life cycle from preuse through to stabilised use, and it is a readily accessible and quite parsimonious model. It also explicitly distinguishes between adaptation and stabilisation (although the latter is referred to, somewhat confusingly, as appropriation), as well as incorporating the adoption decision and the possibility of technology rejection occurring after a period of use. In addition, the model highlights the role of influences in shaping users' evaluations and associated patterns of appropriation throughout the process, although, due to the generic nature of the model, these influences are not specified and are assumed to vary across technologies and cohorts (Carroll, 2004). Nevertheless, in describing the model, Carroll (2004) argues that the features of the technology are particularly important when first encountering a technology, with system usefulness becoming more salient as users apply the technology in context.

The model shares concepts from the models and theories described earlier. The concept of 'spirit', also used by DeSanctis and Poole (AST), is drawn on to help describe the 'technology as designed'. The MTA incorporates the concept of mutual shaping or adaptation, like AST. The MTA includes the decision to adopt as an outcome of initial exposure, as does Rogers (1995). The MTA therefore provides a means of describing use of technology over time in a way that is quite nuanced, as well as being consistent with prior research; however, the model emphasises description over explanation and prediction, which is not unexpected given that the model emerged from empirical research. It therefore does not provide much in the way of insights as to the underpinning or generative mechanisms that shape users evaluations and patterns of appropriation, other than to flag the need to identify the particular influences operating on users' evaluations of a particular technology. 


\section{Identification and Development of a Theory for Understanding the Use Life Cycle}

Each of the theories or models considered above has a variety of strengths and weaknesses that can assist in understanding one or more aspects of the use life cycle, which are summarised in Table 4.2.

Table 4.2 Relative Strengths of Theories for Understanding the Use Life Cycle

\begin{tabular}{|c|c|c|c|c|}
\hline Relative strength & $\begin{array}{l}\text { Technology } \\
\text { acceptance }\end{array}$ & $\begin{array}{l}\text { Innovation } \\
\text { diffusion }\end{array}$ & Structuration & MTA \\
\hline $\begin{array}{l}\text { Consideration of whole use } \\
\text { life cycle }\end{array}$ & Low & Medium & Low & High \\
\hline Accessibility/parsimony & High & High & Low & High \\
\hline $\begin{array}{l}\text { Understanding of dynamics } \\
\text { of influences on and patterns } \\
\text { of use }\end{array}$ & Low-medium & Low-medium & Medium & High \\
\hline $\begin{array}{l}\text { IT artefacts considered at } \\
\text { micro-level (not black boxed) }\end{array}$ & Low & Low & High & High \\
\hline $\begin{array}{l}\text { Ability to explain process of } \\
\text { change (explanatory power) }\end{array}$ & Low-medium & Low-medium & Medium-high & Low-medium \\
\hline $\begin{array}{l}\text { Inductive/empirical basis for } \\
\text { model }\end{array}$ & Low & Medium & Low & High \\
\hline $\begin{array}{l}\text { Applied to range of user } \\
\text { cohorts and use contexts }\end{array}$ & High & High & High & Medium \\
\hline $\begin{array}{l}\text { Consideration of mutual } \\
\text { adaptation/bidirectional } \\
\text { causality }\end{array}$ & Low & Medium & High & High \\
\hline $\begin{array}{l}\text { Focus on adaptation and } \\
\text { stabilisation }\end{array}$ & Low & Medium & High & High \\
\hline $\begin{array}{l}\text { Stabilisation not privileged } \\
\text { over adaptation }\end{array}$ & Low & Low & Low & Medium \\
\hline Consideration of context & Low & Low & High & High \\
\hline $\begin{array}{l}\text { Consideration of minimal use, } \\
\text { rejection behaviour }\end{array}$ & Low & Medium & Medium & High \\
\hline Cumulative tradition & High & High & Medium & Low \\
\hline $\begin{array}{l}\text { Understanding of } \\
\text { heterogeneity of use across } \\
\text { individuals }\end{array}$ & Low & Low-medium & Medium & High \\
\hline
\end{tabular}

Understanding the whole life cycle of IT use is of central concern in this research. Only the MTA provides coverage across the entire life cycle from pre-use through to stabilisation. The model also facilitates understanding of the dynamics of influences on and patterns of use, and does so in a way that is readily accessible and quite parsimonious. Furthermore, it considers technology and relationships with users at the micro-level of analysis. It is for these reasons, as well as the additional strengths listed in Table 4.2, that the MTA is the most promising candidate theory for understanding the whole life cycle of IT use. There are, 
however, two areas where the MTA is less strong: its ability to explain the how and why of the appropriation process, and the limited cumulative tradition. The latter issue is addressed through drawing on the MTA in this chapter, thereby contributing to the ongoing establishment of a cumulative tradition. The former concern about explanatory power is addressed quite well in structurational models like AST, but such power is diminished by their low accessibility and parsimony. What are required are theories of change that complement the MTA by enhancing the capacity to explain the appropriation process in a way that is readily accessible.

Van de Ven and Poole (1995) reviewed theories of change in the biological, physical and social sciences. They identified four 'ideal type' theories of change: life cycle, teleology, dialectic and evolution. The MTA provides largely a life-cycle perspective on the change process whereby change is explained in terms of a sequence of phases through which the system of interest passes. The progression through the phases is presumed to follow a certain immanent logic or sequence that is pre-programmed. While the environment influences how the entity expresses itself, such as the particular patterns of adaptation and stabilisation, as well as their timing, these types of change events are nevertheless mediated by the immanent logic, or what Van de Ven and Poole (1995) referred to more broadly as the generative mechanism. The use of a life-cycle perspective provides a way of generating rich descriptions of the entity of interest. It is, however, somewhat limited with respect to explaining how and why the entity of interest changes or remains stable over time. This constraint can be overcome by juxtaposing additional theories of change and their associated generative mechanisms.

A teleological perspective frames change as being driven by the purposeful pursuit of goals (Van de Ven and Poole, 1995). The generative mechanism is the enactment of goals, which in the IT domain would be undertaken by users or organisations. Users or organisations are seen to act as intentional agents working to achieve the fulfilment of their goals. Furthermore, these agents are presumed to be adaptive and creative in formulating and enacting their goals. Unlike life-cycle theories there is no prescribed sequence. Instead, there is 'a repetitive sequence of goal formulation, implementation, evaluation, and modification of goals based on what was learned or intended by the entity' (p. 516). Theories in IS that draw on cognitive rational theories, such as many theories of acceptance and innovation diffusion, similarly assume that change is driven by the intentionality of users, with users' intentions being informed by their beliefs and attitudes towards the technology of interest (Pfeffer, 1982).

Dialectic theories explain stability and change by reference to the tension that exists between opposing or contradictory forces, such as that between advocates of the status quo, the thesis and those promoting change-the antithesis (Van de Ven and Poole, 1995). The types of outcomes resulting from 
tensions can be understood in terms of maintenance, substitution or synthesis. Maintenance describes the continuance of the status quo, with the thesis dominating the antithesis. Substitution occurs when the thesis is replaced with the antithesis. The third possible outcome is a synthesis between the thesis and antithesis - an outcome that is distinct from its constituent elements. The generative mechanism or motor of change in dialectic theories is the tension or conflict that exists between opposing forces. None of the theories considered here clearly represents or draws on a dialectic perspective, although there are examples of such theories being employed in IS (Cho et al., 2007; Myers, 1994; Robey and Boudreau, 1999; Robey et al., 2002). Giddens' structuration theory incorporates dialectic elements by identifying the possible tensions that exist between human agency and the structural properties of the contexts within which humans are embedded. The synthesis from this tension is the process of mutual constitution of agency and structural properties; however, it is not clear how agency or structure could exist independently of the other, as is the case in the dialectic theories described by Van de Ven and Poole (1995).

Evolutionary theory views and explains change as occurring through a continuous process of variation, selection and retention (Van de Ven and Poole, 1995). Variation comes about due to random or unpredictable changes or events. Selection occurs through competition for scarce resources in the environment. Retention refers to maintenance of an entity's form; it serves to counteract the 'self-reinforcing loop between variations and selection' (p. 518). An evolutionary perspective therefore captures the tension between change and inertia associated with the status quo or temporary stabilisations. The role of unpredictable discrepant events in explaining additional adaptations in the research by Tyre and Orlikowski (1994) is an example of research that is consistent with an evolutionary perspective. There are studies that have also more explicitly drawn on one or more aspects of evolutionary theory in the IS domain such as coevolution (Fidock, 2002; Kim and Kaplan, 2006) and punctuated equilibrium (Lyytinen and Newman, 2008; Mendoza et al., 2007; Sabherwal et al., 2001).

The teleological, dialectic and evolutionary lenses, together with the lifecycle perspective offered by the MTA, offer the potential for providing greater understanding of the life cycle of IT use than would be provided by drawing on only one theoretical perspective. This is because particular theoretical perspectives, as metaphorical devices or lenses, draw attention to particular features or qualities whilst also leaving out others. It is the integration and juxtaposition of these theories to develop new theory that has stronger and broader explanatory power than the initial perspectives (Van de Ven and Poole, 1995). Through incorporating the theories of change, the explanatory power of the MTA is enhanced. This is summarised in Figure 4.7. Each of the theories of change offers alternative and complementary explanations of why 
appropriations change over time. The contribution of each theory of change to enhancing the MTA is now examined through the case of electronic mail in the Defence Science and Technology Organisation (DSTO). Due to space limitations, consideration is limited to the separate contributions of each change theory. Future work will examine the ways in which the theories can be combined and sequenced to further enhance explanation.

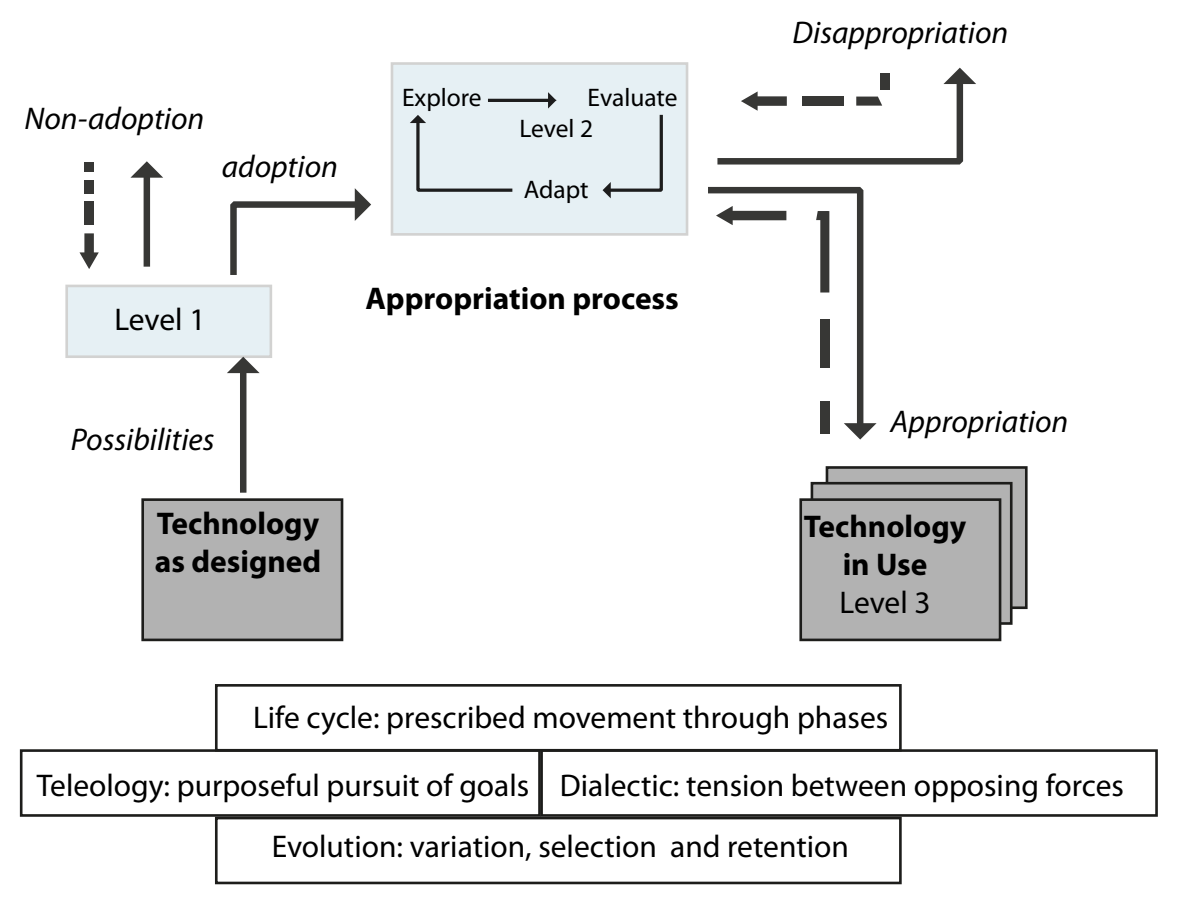

Figure 4.7 An Enhanced Theory for Explaining the IT Life Cycle

Source: Adapted from Carroll (2004, p. 5)

\section{Explaining the IT Use Life Cycle: The case of email}

\section{Life Cycle}

In DSTO, email is a mature and pervasive technology that is thoroughly incorporated with peoples' practices to become a 'technology in use'. Furthermore, the amount of exposure of individuals to this technology was substantial and ranged from four to 28 years. In the MTA, 'technology in use' is associated with stabilisation in patterns of appropriation. There was evidence of stability, such as frequency of filing messages and the way email was managed. Also consistent with the MTA, there was evidence of adaptations occurring to the default configuration of MS Outlook 2003 after its introduction, such as 
turning off the reading pane or turning off the message reminders, followed by stability in these reconfigurations. There were also instances of people making further changes to their configurations as a result of reflecting on how their current configuration might not readily support desired practices; deciding, for example, to turn off the message reminders after discussing this feature with the researcher. The MTA therefore provides a way of describing phases through which users might pass: adaptation, followed by stabilisation then renewed adaptation.

Another feature of the MTA is the proposition that users' trajectories with respect to how they come to adopt, adapt and incorporate technologies with their practices are heterogeneous. There was substantial heterogeneity in patterns of appropriation across individuals with respect to such things as approaches to email management, rhythms of use and number of messages sent and received. As Mackay (1988) found in her study more than 20 years ago, the 'use of electronic mail is strikingly diverse, although not infinitely so' (p. 344).

\section{Teleology}

A multilevel examination of teleology was undertaken providing an assessment of individual and organisational goals associated with use of email (Jasperson et al., 2005; van den Hooff, 2005). During the data collection for this case, DSTO made investments in two technologies designed to better support users in managing emails (Enterprise Vault) and to communicate via computer more dynamically (MS Communicator, which provides instant messaging). Enterprise Vault was introduced to assist DSTO in meeting its archiving responsibilities and to support staff in archiving and managing their messages. MS Communicator was deployed in an effort to provide staff with modern office communication technologies. These investments clearly influenced some users' patterns of appropriation, like an interviewee who had moved to using MS Communicator to support social communication needs in the workplace.

A range of belief and attitudinal influences, such as usability and usefulness, was assessed in this case. None of these influences was significantly related with any of the measures of appropriation. This is perhaps due to much of email users' appropriations not being goal directed but determined by habitual routines, such as rhythms of use, as well as by contextual influences, such as the nature of a job. This finding is consistent with the proposition put forward by Venkatesh et al. (2003) that such influences might be less likely to apply where behaviour is generated by routinised responses, rather than resulting from deliberate cognitions. Nevertheless, there was widespread evidence from the qualitative data that many of the participants had acted intentionally when changing their patterns of appropriation. The reasons given 
for making intentional changes included reflection on extant practices associated with email use, the introduction of other technologies and the patterns of use and suggestions of other people.

A teleological perspective draws attention to the purposeful pursuit of goals. Prior research has found that email is not only 'strikingly diverse' but that it also supports multiple goals (Wattenberg et al., 2005). In DSTO, email was used to support a wide variety of goals such as communication, information management and information sharing.

\section{Dialectics}

Dialectic process theory explains stability and change as the outcome of tensions between opposing or competing entities (Van de Ven and Poole, 1995). Tensions were analysed at the level of the email artefact and at the level of users' practices and associated technologies. Interviewees were asked to generate email similes. Ambivalence towards email was a prominent feature of these similes. For example, it is a 'necessary evil' that supports information exchange (thesis) but which also has a big impact on time (antithesis). Ambivalence represented the emotional synthesis resulting from tensions between the affordances (thesis) and constraints (antithesis) of email.

As has been discussed, email supports a variety of goals associated with communications, information management and information sharing (the thesis). There are other channels and technologies that also support the fulfilment of these goals, particularly face-to-face and telephone (the antithesis). The use of email, face-to-face, phone and other means of communication therefore provided users with a portfolio of channels and technologies to support the fulfilment of these goals (the synthesis).

Two technologies associated with communications and information management were introduced during the data collection phase of this case: Enterprise Vault and MS Communicator. These technologies represented the antithesis to the existing portfolio of technologies and practices associated with email (the thesis). Enterprise Vault was deployed to all desktops, with users having the option of installing MS Communicator if they so desired. Some individuals embraced these new technologies by incorporating them into their portfolios, as well as by adjusting their practices. The incorporation of the technologies with existing portfolios represented a synthesis. Also apparent were substitutions in functionality or affordances. Activities like informal communications and archiving that were previously undertaken using email were now performed using these new technologies. For example, one individual moved all of his archived messages back into his inbox so that they would all be located in the one place, with archiving of the inbox now done automatically by Enterprise 
Vault, which in turn facilitated easier searching. Another individual had substituted email with MS Communicator to support informal communication and coordination amongst a walking group. The majority of other participants had not changed the location of their folders to their inbox to take advantage of the capabilities of Enterprise Vault, instead maintaining folders on their local PC or on a shared drive. They also had not installed MS Communicator.

\section{Evolution}

Evolution entails a continuous cycle of variation, selection and retention. Processes of variation and selection are associated with adaptations; retention is associated with stabilisations. All of these processes were manifested in this case.

Variations result from unpredictable events. Four interviewees identified accidents and incidents as influences on changes to their patterns of appropriation. One individual had previously kept all deleted items just in case he needed them, but accidentally deleted them one day and 'the sky didn't fall in'. From this point on, he decided to be 'a little more ruthless in culling things'. Similarly, another person had accidentally bulk deleted the messages in her inbox with no consequences. She subsequently decided to consciously bulk delete messages. Both of these accidents can be seen to have led to more efficient use of their time resources, the result of which was the selection of new email deletion practices.

Participants' patterns of appropriation were typified by both adaptation and inertia (retention). Participants retained similar patterns over time for checking and filing messages, messages sent, inbox size, number of folders and the type of email management approach adopted (inbox centric, folder centric or a combination). Furthermore, the majority of participants perceived their use of email as habitual.

\section{The MTA Enhanced}

Why did users' appropriations of email vary? From the perspective of the MTA, adaptations and stabilisations of patterns of appropriations were found, as was variability across individuals. All of these features are found in the MTA, and the sequencing of phases - adaptation then stabilisation then renewed adaptation - was also manifested. This provides a limited answer, however, to the 'why' question. An enhanced understanding of the process of appropriation was provided by examining the results from the perspective of three additional theories of change: teleology, dialectic and evolution. 
- A multilevel view of intentionality assisted in providing a richer assessment of the rationale for changes in users' patterns of appropriation. Belief and attitudinal measures did not significantly influence users' appropriations, perhaps in part due to the lack of intentionality associated with various routinised patterns of appropriations. Nevertheless, many of the changes in patterns were intentional and were explained by reference to a variety of context-specific influences.

- Ambivalence was an important emotional synthesis that emerged from the tensions between the affordances and constraints of email. Email formed part of users' portfolios of communication channels and associated technologies that included phone, face-to-face and a variety of other channels. These channels and technologies were synthesised by users to create their portfolios. The process of synthesising new technologies into users' portfolios was also accompanied by substitution of affordances from the old onto the new.

- Accidents and incidents served as important influences on changes to patterns of appropriation for some users. Furthermore, the translation of the accidents into the selection of alternative appropriations was facilitated by the unintended efficiency gains derived from the accidents.

\section{Conclusion}

In this chapter the life cycle of IT use has been briefly outlined. A range of theories used to explain use has been considered and a candidate theory well suited to explaining the life cycle of use has been selected: the MTA. The MTA covers the entire life cycle from pre-use through to stablised use, as well as incorporating many of the strengths of the other theories and models. The MTA, however, is somewhat weak with respect to explaining the how and why of changes in patterns of use over the life cycle. The MTA largely relies on explanation by reference to an immanent logic as users move from one phase to another. For example, in the email case, adaptation was followed by stabilisation. To enhance explanation of the IT use life cycle, additional theories of change need to be incorporated. A teleological lens assists in explaining organisational and individual intentions associated with changes, such as the introduction of new technologies associated with email, as well as explaining how contextual influences contribute to changes in users' intentions and behaviours. The dialectic lens provides a way of explaining the substitutions, syntheses and maintenance of the status quo associated with certain patterns of appropriation over time. Finally, the evolutionary lens helps to explain how accidents and incidents play a role in shaping user behaviours and choices in the context of an environment constrained by limited time resources. To paraphrase Van de Ven and Poole (1995), it is the integration of these additional theories of change with the MTA that has led to the development of a new theory - the enhanced 
MTA - which has stronger and broader explanatory power than the original MTA. In so doing, the enhanced MTA represents an important contribution to theorising about the life cycle of IT use.

\section{References}

Abraham, C., \& Sheeran, P. (2004). Implications of goal theories for the theories of reasoned action and planned behavior. In C. Armitage \& J. Christian (eds), Planned Behavior: The relationship between human thought and action (pp. 101-22). New Brunswick, NJ: Transaction Publishers.

Adams, D. A., Nelson, R. R., \& Todd, P. A. (1992). Perceived usefulness, ease of use, and usage of information technology: a replication. MIS Quarterly, $16(2), 227-47$.

Agarwal, R., \& Prasad, J. (1998). The antecedents and consequents of user perceptions in information technology adoption. Decision Support Systems, 22(1), 15-29.

Ajzen, I. (1985). From intentions to actions: a theory of planned behavior. In J. Kuhl \& J. Beckmann (eds), Action Control: From cognition to behavior (pp. 11-39). New York, NY: Springer Verlag.

Al-Gahtani, S., \& King, M. (1999). Attitudes, satisfaction and usage: factors contributing to each in the acceptance of information technology. Behaviour and Information Technology,18(4), 277-97.

Bagozzi, R. P. (2007). The legacy of the technology acceptance model and a proposal for a paradigm shift. Journal of the Association for Information Systems, 8(4), 244-54.

Baker, E. (2007). Technology and its discontents. Strategy+Business, 31 July. Retrieved from <http://www.strategy-business.com $>$

Barley, S. R. (1986). Technology as an occasion for structuring: evidence from observations of CT scanners and the social order of radiology departments. Administrative Science Quarterly, 31(1), 78-108.

Baron, S., Patterson, A., \& Harris, K. (2006). Beyond technology acceptance: understanding consumer practice. International Journal of Service Industry Management, 17(2), 111-35.

Benbasat, I., \& Barki, H. (2007). Quo vadis, TAM? Journal of the Association for Information Systems, 8(4), 211-18. 
Benbasat, I., \& Zmud, R. W. (2003). The identity crisis within the IS discipline: defining and communicating the discipline's core properties. MIS Quarterly, 27(2), 183-94.

Bhattacherjee, A., \& Premkumar, G. (2004). Understanding changes in belief and attitude toward information technology usage: a theoretical model and longitudinal test. MIS Quarterly, 28(2), 229-54.

Boersma, K., \& Kingma, S. (2005). From means to ends: the transformation of ERP in a manufacturing company. The Journal of Strategic Information Systems, 14(2), 197-219.

Burton-Jones, A. \& Straub, D. W., jr (2006). Reconceptualizing system usage: an approach and empirical test. Information Systems Research, 17(3), 228-46.

Carayannis, E. G., \& Turner, E. (2006). Innovation diffusion and technology acceptance: the case of PKI technology. Technovation, 26(7), 847-55.

Carroll, J. (2004). Completing design in use: closing the appropriation cycle. Paper presented at the Twelfth European Conference on Information Systems (ECIS 2004), Turku, Finland.

Carroll, J., Howard, S., Murphy, J., \& Peck, J. (2002a). 'No' to a free mobile: when adoption is not enough. Proceedings of the $13^{\text {th }}$ Australasian Conference on Information Systems (ACIS 2002), Melbourne, Australia.

Carroll, J., Howard, S., Peck, J., \& Murphy, J. (2002b). A field study of perceptions and use of mobile telephones by 16 to 22 year olds. Journal of Information Technology Theory and Application, 4(2), 49-61.

Carroll, J., Howard, S., Peck, J., \& Murphy, J. (2003a). From adoption to use: the process of appropriating a mobile phone. Australasian Journal of Information Systems, 10(2), 38-48

Carroll, J., Howard, S., Vetere, F., Peck, J., \& Murphy, J. (2002c). Just what do the youth of today want? Technology appropriation by young people. Proceedings of the $35^{\text {th }}$ Annual Hawaii International Conference on Systems Sciences (HICSS 2002), 1777-85.

Carroll, J., Kriss, S., \& Murphy, J. (2003b). Developing CRM systems that encourage user uptake. Proceedings of the $7^{\text {th }}$ Customer Contact World Conference, Sydney, Australia.

Carroll, J., Mendoza, A., \& Stern, L. (2005). Adoption, adaptation, stabilization and stagnation: software appropriation over time. Proceedings of the $16^{\text {th }}$ Australasian Conference on Information Systems (ACIS 2005), Sydney, Australia. 
Chin, W. W., Gopal, A., \& Salisbury, W. D. (1997). Advancing the theory of adaptive structuration: the development of a scale to measure faithfulness of appropriation. Information Systems Research, 8(4), 342-67.

Cho, S., Mathiassen, L., \& Robey, D. (2007). Dialectics of resilience: a multi-level analysis of a telehealth innovation. Journal of Information Technology, 22(1), $24-35$.

Chu, T.-H., \& Robey, D. (2008). Explaining changes in learning and work practice following the adoption of online learning: a human agency perspective. European Journal of Information Systems, 17(1), 79-98.

Constantinides, P., \& Barrett, M. (2006). Negotiating ICT development and use: the case of a telemedicine system in the healthcare region of Crete. Information and Organization, 16(1), 27-55.

Cooper, R. B., \& Zmud, R. W. (1990). Information technology implementation research: a technological diffusion approach. Management Science, 36(2), 123-39.

Davis, F. D. (1989). Perceived usefulness, perceived ease of use, and user acceptance of information technology. MIS Quarterly, 13(3), 319-40.

Davis, F. D. (1993). User acceptance of information technology: system characteristics, user perceptions and behavioral impacts. International Journal of Man-Machine Studies, 38(3), 475-87.

Davis, F. D., Bagozzi, R. P., \& Warshaw, P. R. (1989). User acceptance of computer technology: a comparison of two theoretical models. Management Science, 35(8), 982-1003.

DeLone, W. H., \& McLean, E. R. (1992). Information systems success: the quest for the dependent variable. Information Systems Research, 3(1), 60-95.

DeSanctis, G., \& Poole, M. S. (1994). Capturing the complexity in advanced technology use: adaptive structuration theory. Organization Science, 5(2), $121-47$.

DeSanctis, G., Poole, M. S., \& Dickson, G. W. (2000). Teams and technology: interactions over time. Research on Managing Groups and Teams, 3, 1-27.

Desouza, K. C., Awazu, Y., \& Ramaprasad, A. (2007). Modifications and innovations to technology artifacts. Technovation, 27(4), 204-20.

Dishaw, M. T., \& Strong, D. M. (1999). Extending the technology acceptance model with task-technology fit constructs. Information and Management, 36(1), 9-21. 
Fidock, J. (2002). From evaluation to action: supporting the co-evolution of business practices and IT in the government sector. Proceedings of the $9^{\text {th }}$ European Conference on the Evaluation of IT (ECITE), Paris, France.

Giddens, A. (1986). The Constitution of Society: Outline of the theory of structuration. Berkeley, Calif.: University of California Press.

Goodhue, D. L. (2007). Comment on Benbasat and Barki's 'Quo vadis TAM' article. Journal of the Association for Information Systems, 8(4), 219-22.

Gopal, A., Bostrom, R. P., \& Chin, W. W. (1992). Applying adaptive structuration theory to investigate the process of group support systems use. Journal of Management Information Systems, 9(3), 45-69.

Hage, J., \& Aiken, M. (1970). Social Change in Complex Organizations. New York, NY: Random House.

Hayes, N. (1999). Work-arounds and boundary crossing in a high tech optronics company: the role of co-operative workflow technologies. Computer Supported Cooperative Work, 9(3-4), 435-55.

Herszfeld, S., Carroll, J., \& Howard, S. (2003). Job allocation by SMS: technology appropriation in the construction industry. Proceedings of the $14^{\text {th }}$ Australasian Conference on Information Systems (ACIS 2003), Perth, Australia.

Heung, R. (2002). An evaluation of the model of technology appropriation, Honours thesis, University of Melbourne, Melbourne, Australia. Retrieved from <http://wwwtest.dis.unimelb.edu.au/future/research/theses/2002/ HEUNG\%282002\%29_abstract.pdf>

Hirschheim, R. (2007). Introduction to the special issue on 'Quo vadis TAMissues and reflections on technology acceptance research'. Journal of the Association for Information Systems, 8(4): 203-5.

Hovorka, D. S., Germonprez, M., \& Larsen, K. R. (2008). Explanation in information systems. Information Systems Journal, 18(1), 23-43.

Hsieh, J., Rai, A., \& Keil, M. (2008). Understanding digital inequality: comparing continued use behavioral models of the socio-economically advantaged and disadvantaged. MIS Quarterly, 32(1), 97-126.

Hubona, G., \& Geitz, S. (1997). External variables, beliefs, attitudes and information technology usage behavior. Proceedings of the $30^{\text {th }}$ Annual Hawaii International Conference on System Sciences (HICSS 97), Wailea, HI, 3, 21-8.

Igbaria, M. (1990). End-user computing effectiveness: a structural equation model. Omega, 18(6), 637-52. 
Igbaria, M., Pavri, F. N., \& Huff, S. L. (1989). Microcomputer applications: an empirical look at usage. Information and Management, 16(4), 187-96.

Igbaria, M., Zinatelli, N., Cragg, P., \& Cavaye, A. L. M. (1997). Personal computing acceptance factors in small firms: a structural equation model. MIS Quarterly, 21(3), 279-305.

Jasperson, J., Carter, P. E., \& Zmud, R. W. (2005). A comprehensive conceptualization of post-adoptive behaviors associated with information technology enabled work systems. MIS Quarterly, 29(3), 525-57.

Johnson, B. M., \& Rice, R. E. (1984). Reinvention in the innovation process: the case of word processing. In R. E. Rice (ed.), The New Media: Communication, research, and technology (pp. 157-83). Beverly Hills, Calif.: Sage.

Jones, M. R., \& Karsten, H. (2008). Giddens's structuration theory and information systems research. MIS Quarterly, 32(1), 127-57.

Karahanna, E., Straub, D. W., \& Chervany, N. L. (1999). Information technology adoption across time: a cross-sectional comparison of pre-adoption and postadoption beliefs. MIS Quarterly, 23(2), 183-213.

Kautz, K., \& Larsen, E. A. (2000). Diffusion theory and practice: disseminating quality management and software process improvement innovations. Information Technology \& People, 13(1), 11-26.

Kim, R. M., \& Kaplan, S. M. (2006). Interpreting socio-technical co-evolution: applying complex adaptive systems to IS engagement. Information Technology \& People, 19(1), 35-54.

King, N. (1990). Innovation at work: the research literature. In M. A. West \& J. L. Farr (eds), Innovation and Creativity at Work: Psychological and organizational strategies (pp. 15-59). Oxford, UK: John Wiley \& Sons.

Kraut, R. E., Rice, R. E., Cool, C., \& Fish, R. S. (1998). Varieties of social influence: the role of utility and norms in the success of a new communication medium. Organization Science, 9(4), 437-53.

Kwon, T. H., \& Zmud, R. W. (1987). Unifying the fragmented models of information systems implementation. In R. J. Boland \& R. A. Hirschheim (eds), Critical Issues in Information Systems Research (pp. 227-51). New York, NY: John Wiley \& Sons.

Lee, A. S. (1999). Researching MIS. In W. L. Curry \& R. Galliers (eds), Rethinking Management Information Systems (pp. 7-27). Oxford, UK: Oxford University Press. 
Leonard-Barton, D. (1988). Implementation as mutual adaptation of technology and organization. Research Policy 17(5), 251-67.

Lin, H.-F., \& Lee, G.-G. (2006). Effects of socio-technical factors on organizational intention to encourage knowledge sharing. Management Decision, 44(1), 7488 .

Lucas, H. C., jr, Swanson, E. B., \& Zmud, R. W. (2007). Implementation, innovation, and related themes over the years in information systems research. Journal of the Association for Information Systems, 8(4), 206-10.

Lyytinen, K., \& Newman, M. (2008). Explaining information systems change: a punctuated socio-technical change model. European Journal of Information Systems, 17(6), 589-613.

Mackay, W. E. (1988). More than just a communication system: diversity in the use of electronic mail. Proceedings of the 1988 ACM Conference on ComputerSupported Cooperative Work (CSCW 88), Portland, Ore., 344-53.

Mackay, W. E. (1990a). Patterns of sharing customizable software. Proceedings of the 1990 ACM Conference on Computer-Supported Cooperative Work (CSCW 90), Los Angeles, Calif., 209-21.

Mackay, W. E. (1990b). Users and customizable software: a coadaptive phenomenon. Doctoral dissertation, Massachusetts Institute of Technology, Cambridge, Mass.

McLean, E., Seddon, P., Torkzadeh, R., \& Wilcocks, L. (2002). IS success measurement: guidelines for future research. Proceedings of the Twenty-Third International Conference on Information Systems (ICIS 2002).

McMaster, T., \& Wastell, D. (2005). Diffusion — or delusion? Challenging an IS research tradition. Information Technology \& People, 18(4), 383-404.

Majchrzak, A., Rice, R. E., Malhotra, A., King, N., \& Ba, S. (2000). Technology adaptation: the case of a computer-supported inter-organizational virtual team. MIS Quarterly, 24(4), 569-600.

Markus, M. L., \& Silver, M. S. (2008). A foundation for the study of IT effects: a new look at DeSanctis and Poole's concepts of structural features and spirit. Journal of the Association for Information Systems, 9(10), 609-32.

Mathieson, K. (1991). Predicting user intentions: comparing the technology acceptance model with the theory of planned behavior. Information Systems Research, 2(3), 173-91. 
Mendoza, A., Carroll, J., \& Stern, L. (2005). Adoption, adaptation, stabilization and stagnation: software appropriation over time. Proceedings of the $16^{\text {th }}$ Australasian Conference on Information Systems (ACIS 2005), Sydney, Australia.

Mendoza, A., Carroll, J., \& Stern, L. (2008). Influences on continued use of an information system: a longitudinal study. Proceedings of the $16^{\text {th }}$ European Conference on Information Systems (ECIS), Galway, Ireland.

Mendoza, A., Stern, L., \& Carroll, J. (2007). Plateaus in long-term appropriation of an information system. Proceedings of the $18^{\text {th }}$ Australasian Conference on Information Systems (ACIS 2007), Toowoomba, Australia.

Mintzberg, H., \& Westley, F. (2001). Decision-making: it's not what you think. MIT Sloan Management Review, 42(3) 89-93.

Moore, G. C., \& Benbasat, I. (1991). Development of an instrument to measure the perceptions of adopting an information technology innovation. Information Systems Research, 2(3), 192-222.

Myers, M. D. (1994). Dialectical hermeneutics: a theoretical framework for the implementation of information systems. Information Systems Journal, 5(1), 51-70.

Nord, W. R., \& Tucker, S. (1987). Implementing Routine and Radical Innovations. San Francisco, Calif.: New Lexington Press.

Nor Zairah, A. R., \& Rose Alinda, A. (2007). Open source software appropriation: attractor and repellent criteria of a city council. Paper presented at the MMU International Symposium on Information and Communications Technologies (M2USIC 2007).

Ogden, J. (2003). Some problems with social cognition models: a pragmatic and conceptual analysis. Health Psychology, 22(4), 424-8.

Orlikowski, W. J. (1992). The duality of technology: rethinking the concept of technology in organizations. Organization Science, 3(3), 398-427.

Pfeffer, J. (1982). Organizations and Organization Theory. Marshfield, Mass.: Pitman.

Pollard, C. (2003). Exploring continued and discontinued use of IT: a case study of OptionFinder, a group support system. Group Decision and Negotiation, 12(3), 171-93. 
Poole, M. S., \& DeSanctis, G. (1990). Understanding the use of group decision support systems: the theory of adaptive structuration. In J. Fulk \& C. Steinfield (eds), Organizations and Communication Technology (pp. 173-93). Beverly Hills, Calif.: Sage.

Pozzebon, M. (2004). The influence of a structurationist view on strategic management research. Journal of Management Studies, 41(2), 247-72.

Prescott, M. B., \& Conger, S. A. (1995). Information technology innovations: a classification by IT locus of impact and research approach. Data Base Advances, 26(2-3), 20-41.

Raymond, L. (1985). Organizational characteristics and MIS success in the context of small business. MIS Quarterly, 9(1), 37-52.

Rice, R. E., \& Rogers, E. M. (1980). Reinvention in the innovation process. Science Communication, 1(4), 499-514.

Roberts, P., \& Henderson, R. (2000). Information technology acceptance in a sample of government employees: a test of the technology acceptance model. Interacting with Computers, 12(5), 427-43.

Robey, D., \& Boudreau, M.-C. (1999). Accounting for the contradictory organizational consequences of information technology: theoretical directions and methodological implications. Information Systems Research, $10(2), 167-85$.

Robey, D., Ross, J. W., \& Boudreau, M.-C. (2002). Learning to implement enterprise systems: an exploratory study of the dialectics of change. Journal of Management Information Systems, 19(1), 17-46.

Rogers, E. M. (1995). Diffusion of Innovations. New York, NY: Free Press.

Rose, J., \& Jones, M. (2005). The double dance of agency: a socio-theoretic account of how machines and humans interact. Systems, Signs \& Actions, $1(1), 19-37$.

Rosemann, M., \& Vessey, I. (2008). Toward improving the relevance of information systems research to practice: the role of applicability checks. MIS Quarterly, 32(1), 1-22.

Sabherwal, R., Hirschheim, R., \& Goles, T. (2001). The dynamics of alignment: insights from a punctuated equilibrium model. Organization Science, 12(2), 179-97. 
Saga, V. L., \& Zmud, R. W. (1994). The nature and determinants of IT acceptance, routinization and infusion. Proceedings of the IFIP TC8 Working Conference on Diffusion, Transfer and Implementation of Information Technology, 67-86.

Salisbury, D., Chin, W. W., Gopal, A., \& Newsted, P. R. (2002). Research report: better theory through measurement-developing a scale to capture consensus on appropriation. Information Systems Research, 13(1), 91-103.

Schwarz, A., \& Chin, W. (2007). Looking forward: toward an understanding of the nature and definition of IT acceptance. Journal of the Association for Information Systems, 8(4), 230-43.

Sharma, R., \& Yetton, P. (2001). An evaluation of a major validity threat to the technology acceptance model [research in progress]. Proceedings of the $9^{\text {th }}$ European Conference on Information Systems, Bled, Slovenia, 1170-5.

Shih, H.-P. (2008). Continued use of a Chinese online portal: an empirical study. Behaviour and Information Technology, 27(3), 201-9.

Silva, L. (2007). Post-positivist review of technology acceptance model. Journal of the Association for Information Systems, 8(4), 255-66.

Straub, D. W., jr, \& Burton-Jones, A. (2007). Veni, vidi, vici: breaking the TAM logjam. Journal of the Association for Information Systems, 8(4), 223-9.

Sundaram, S., Schwarz, A., Jones, E., \& Chin, W. W. (2007). Technology use on the front line: how information technology enhances individual performance. Journal of the Academy of Marketing Science, 35(1), 101-12.

Taylor, S., \& Todd, P. A. (1995a). Assessing IT usage: the role of prior experience. MIS Quarterly, 19(4), 561-70.

Taylor, S., \& Todd, P. A. (1995b). Understanding information technology usage: a test of competing models. Information Systems Research, 6(2), 144-76.

Trice, A. W., \& Treacy, M. E. (1988). Utilization as a dependent variable in MIS research. Data Base, 19(3-4), 33-41.

Trigg, R. H., \& Bødker, S. (1994). From implementation to design: tailoring and the emergence of systematization in CSCW. Proceedings of the 1994 ACM Conference on Computer Supported Cooperative Work (CSCW 94), 45-54.

Tyre, M. J., \& Orlikowski, W. J. (1994). Windows of opportunity: temporal patterns of technological adaptation in organizations. Organization Science, 5(1), 98-118. 
van den Hooff, B. (2005). A learning process in email use - a longitudinal case study of the interaction between organization and technology. Behaviour \& Information Technology, 24(2), 131-45.

Van de Ven, A., \& Poole, M. S. (1995). Explaining development and change in organizations. Academy of Management Review, 20(3), 510-40.

Van de Ven, A., \& Poole, M. S. (2005). Alternative approaches for studying organizational change. Organization Studies 26(9), 1377-404.

Venkatesh, V., \& Bala, H. (2008). Technology acceptance model 3 and a research agenda on interventions. Decision Sciences, 39(2), 273-315.

Venkatesh, V., Morris, M. G., Davis, G. B., \& Davis, F. D. (2003). User acceptance of information technology: toward a unified view. MIS Quarterly, 27(3), 42578 .

Wattenberg, M., Rohall, S. L., Gruen, D., \& Kerr, B. (2005). E-mail research: targeting the enterprise. Human-Computer Interaction, 20(1-2), 139-62.

Wolfe, R. A. (1994). Organizational innovation: review, critique and suggested research directions. Journal of Management Studies, 31(3), 405-31. 